\title{
Effectiveness of Technology Enabled Psycho-NLP on the Performance of High School Students in Spoken English
}

\author{
E. Ramganesh ${ }^{1} \&$ I. Joseph Milton Paulraj ${ }^{1}$ \\ ${ }^{1}$ Department of Educational Technology, Bharathidasan University, Tiruchiappalli, Tamilnadu, India \\ Correspondence: Dr. E. Ramganesh, Director, UGC-Human Resource Developemnt Centre, Professor and Head, \\ Department of Educational Technology, Bharathidasan University, Tiruchiappalli - 23, Tamilnadu, India. Tel: \\ 91-944-308-5415. \\ Received: June 28, 2016 \\ doi:10.20849/ajsss.v1i2.54 \\ Accepted: July 21, $2016 \quad$ Online Published: August 15, 2016 \\ URL: http://dx.doi.org/10.20849/ajsss.v1i2.54
}

\begin{abstract}
The main objective of this study was to diagnose the problems of std. IX rural students in English language learning and to determine the effect of Psycho NLP on spoken English of rural students since students at rural high schools were not trained to speak in English. School students were not able to speak properly and they form wrong sentences in English (Ranjan, 2013). It is in this context, this experimentation was set to carry out with 24 rural-government school students of IX std.. Single group pre test and post test design was adopted for this study. Students' problems in language learning were assessed with Diagnostic Assessment Scale (DAS). Based on the students' language problems, the content was prepared and integrated in the experimentation. A model "Technology Enabled Psycho-NLP" was developed by the researchers based on literature and studies reviewed that have positive outcomes in NLP. The conceptual, technical and empirical evidences were established for the development of the model. At the end of the experimentation Spoken English of the students was assessed with Spoken English Assessment Scale (SEAS). The result of the study revealed that students taught through the strategy had significant improvements in Spoken English.
\end{abstract}

Keywords: spoken English, technology, psycho-NLP, English language problems

\section{Introduction}

The contemporary position of English in India revealed that English Language Teaching as a second language happens to be at all levels of education. At present, English Language Teaching is enjoying the status of new discipline and has gained due recognition in educational programmes. Reddy Sreenivasulu (2012) views English as the language of knowledge, science \& Technology, a window to the world, Library language and the Language of reason. Half of the world's scientific journals and periodicals are in English. Almost 80\% of the information stored in this word is in English. English is considered to be a language of the planet (Mohanty, 2012). Though the importance of English is obvious still rural people are unaware of the importance of English. According to a survey of 2012, quoted by David (2013) recently, only $4 \%$ of the Indian population is using English. It is imperative to think of the remaining population at rural areas and make them to learn English language. This ideology made the researchers to think deeply and care for the rural learners who are at the need of the hour. It is said that pupils at rural schools were not trained properly to listen, speak, read and write. Singh (2010) stated that students at high schools and colleges were not able to fill the application form in English. Students at high schools manage to communicate with only limited vocabularies. School students fail to reproduce and form correct sentence rather they speak and write wrong sentence (Ranjan, 2013). In this globalization world, speaking in English is considered to be a learned and intelligent. Thus most of the parents are interested to join their children in English medium schools. Institutions also take serious effort on developing spoken skills of students in English (Ranjan, 2013). So, English language learning needs to be strengthened at school levels so that improvement would be found at college levels. Thus, school students were taken cognition for the present study to develop their spoken English. Begagi (2013) pointed out that teaching was one of the main reasons that affected communicative skill of the rural learners. It is suggested to evolve a new strategy or techniques for developing spoken English (Mohanty, 2012). Thus, Neuro Linguistic Programming (NLP) which was found to be effective in education was identified as a new strategy and integrated to teach Spoken English. 


\subsection{Rationale for Integration of NLP for Developing Spoken English}

Neuro Linguistic Programming (NLP) is a field founded by Richard Bandler, a student of Psychology and John Grinder, a then assistant professor of linguistics at California University, Santa Cruz in 1970s (Tosey \& Mathison, 2010). However the origin of NLP is said to be between 1972 to 1981 (Zorica, 2006). NLP is defined as a humanistic psychology dealing with art of communication and studying the structure of subjective excellence (Tosey \& Michelli, 2005) cited by Reza, shayesteh and Shapoorti (2011). Dilts et al. (1980) expresses his view on NLP that a person is a whole mind-body system with pattern connection between the neurological processes (Neuro), language (Linguistic) and behavioural strategies (Programming) cited by Tosey \& Mathison (2010). A spelling strategy for children based on NLP developed by Mally (1989) and Dilts had a significant result in improving the spelling of the children (Kudliskis, Voldis and Burden, Robert, 2009). The usage of NLP techniques in management, medicine, sports, business, law and education was successful (Karunaratre, 2010; Tosey Mathison and Michelli, 2010). NLP is also defined as "an approach to language teaching which is claimed to help achieving excellence in leaners performance" (Millroad, 2004). Hardingham (1998) stated that Neuro Linguistic Programming improved the effectiveness of language teaching (Milroad, 2004). Adopting of NLP principles in language teaching made the language teacher more efficient (Zorica, 2006). The result of the study conducted by Saman (2006) on the effective ways of teaching and learning English through NLP Techniques indicated that NLP helped students to overcome anxiety, unpleasant situation and to create a positive atmosphere and to encourage them to reach their goal in their life. Knowing the inter-relative effectiveness of NLP, the researcher identified NLP for improving Spoken English along with the integration of Technology.

\subsection{Rationale for Integrating Technology into NLP for Developing Spoken English}

Technology and Education will be entangled in future education (Pegrum, 2009). Adopting technology for language learning is increasing. English Language Teaching (ELT) with technology integration is a paradigm shift in educational field. Trucano (2012) stated "enthusiasm for the use of computers and other Information Communication Technology (ICT) in education is undeniable and widespread. Technology mediated language learning has been successful when technology is integrated into language activities (Leask, 2001). "ICT seems to be successful when integrated into project-based language learning" (Beckett and Miller, 2006). It is in this context, the researchers made an attempt to develop a model for developing Spoken English using technology and NLP.

\section{Model Development: "Technology Enabled Psycho-NLP” for Improving Spoken English}

The researchers gained insights to coin the term Psycho-NLP with justifications mentioned here because NLP can be viewed as the operating manual for people's mind that can guide us through the necessary steps to reprogramme our processing mechanism (Good Therapy, 2016. Qualified psychologist also appreciated that development of worthwhile skills, quality teaching and significant practices were possible through NLP training. Hauchar (2016) looks NLP as Neuro Linguistic Psychology stating that it is a powerful method for changing behavior and positive results. It is a integration of several disciplines of neurology, psychology and linguistics. It is a science of how brain codes learning and experience. Ambrose (2016), a psychologist, had been applying NLP to organizational and personal change with great success over the last five years (Collingwood, 2016). Those practicing psychologist who argued their professional carrier development with accelerated graduate-standard NLP training improved their professional result. Charis Collingwood (2016) committed himself to enhance the relationship between Psychology and NLP, exemplified by their current research efforts. However, Hauchar (2016) stated that NLP well grounded in psychology theory, it dealt with the structure of subjective experience, how we see, hear and feel and we edit and filter the outside world through our sense. So, based on the ideologies of the psychologists regarding NLP and technology integration with NLP, the model was named as Technology Enabled Psycho-NLP. The researchers found out the processing area of the students by administering diagnostic assessment test which indicated the areas to be concentrated for developing their language learning. A model based on the principles and techniques of Neuro Linguistic Programming (NLP) integrated with technologies was developed. The model was developed based on literature and studies reviewed that had positive outcomes in NLP. Thus, the conceptual, technical and empirical evidences were established for the development of the model.

\subsection{Functioning of the Model}

This model consisted of three parts - Input, process and output. Input refers to the strategy used to teach the content and give input to the students. Process refers to the content to be processed for the students so that the output, Spoken English, will be achieved. The processing area consists of English grammar and vocabulary that are the insisted in the components of Spoken English. 
Revell and Norman (1997) stated that NLP principles can be applied to the teaching of all aspects of language cited by Zorica (2006). The basic principles of NLP are outcome, rapport creation, sensory awareness and behavioural flexibility. These NLP principles, techniques and appropriate technology were integrated in this model. At the beginning of the class, students are informed clearly the outcome/goal of the class and asked to visualize (visualization) as though they have achieved the outcome of the class because if the learners once tuned they will start to assign their goals and run behind it (Bavister \& Vickers, 2004). Creating and maintaining a good relationship with the students is termed as 'Rapport' (Saman, 2006). NLP suggests ways to create rapport with the students by altering the body language and suiting with their communication called 'mirroring and matching'. When rapport is created with the students, students understand the teacher and teaching becomes successful. Then the teacher has to be aware of what happens in the class because students continuously communicate verbally and non-verbally. Teachers have to study their non-verbal cues and Preferred Representational System (PRS) in order to teach based on their PRS. While being sensitive, if the students are not towards their goal, then teachers are expected to have behavioural flexibility to understand the mind of the learners. Teachers are expected to change the teaching method. Thus, Dilts \& Epstein (1995) suggests exploring different methods of teaching. Since students are having different combination of learning styles, multi sensory approach could be adopted to cater the needs of all types of learners. Even seating arrangements could be changed according to their PRS if needed. Then the outcome, Spoken English, will be improved possibly.

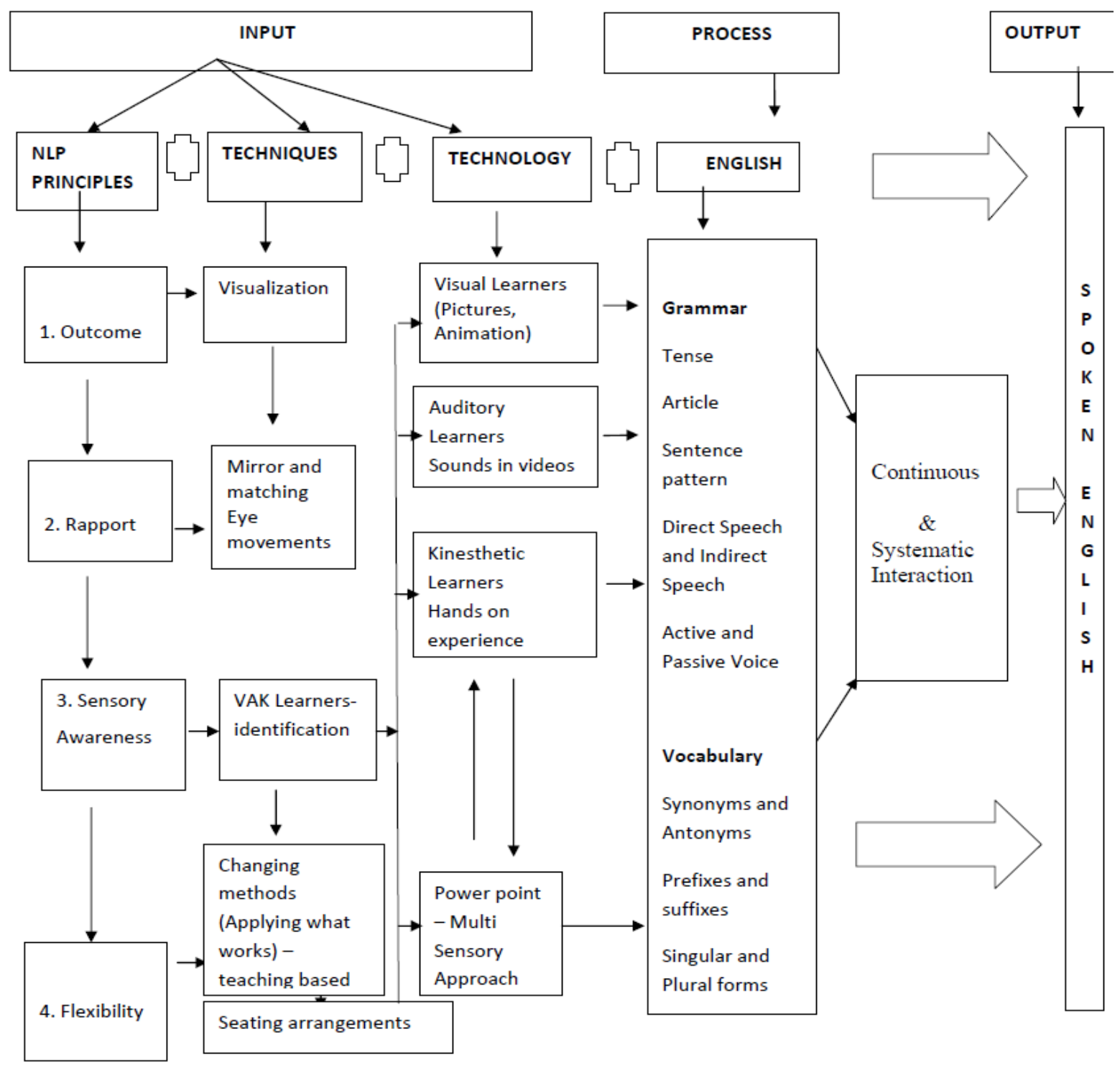

Figure 1. "Technology enabled psycho-NLP” Model for improving spoken English 


\section{Objectives of This Experimentation}

This experiment was attempted to achieve the following main objectives.

1. To ascertain the problems of highs school student in their English language learning.

2. To develop Technology Enabled Psycho-NLP on the basis of the diagnosis to address the problems of the students in Spoken English.

3. To find out the effectiveness of Technology Enabled Psycho-NLP on the performance of High School students in Spoken English.

\section{Hypotheses of the Study}

The following hypotheses were tested to ascertain the achievement of the objectives of the study.

1. Students do not have problems in their English language learning.

2. Technology Enabled Psycho-NLP strategy is effective.

\section{Research Design}

Single group pre test and post test research design was adopted for this study. This experiment was conducted for twenty days with 24 Students from std. IX studying at Rural Government School. Descriptive and differential analyses were made.

\subsection{Construction and Validation of the Tools Used in the Experiment}

a. Diagnostic Assessment Scale

Diagnostic Assessment Scale (DAS) was developed by the researchers to analyse the difficult areas of the learners in English grammar and vocabulary which are considered to be the important components of Spoken English. This DAS was constructed based on the reviews supporting spoken English. The tool was subjected to the experts' opinion to establish face validity and content validity. The tool is reliable since the reliability coefficient of the tool is 0.822 .

\section{b. Spoken English Assessment Scale}

Spoken English Assessment Scale (SEAS) was developed to find out the Spoken English of the students based on the literature and reviews of research in NLP by which conceptual validity was established for the scale. Face validity and Content validity was established with the help of subject experts. The reliability coefficient of the tool is 0.741 . Hence, this tool is considered to have reliability.

\section{Result and Discussion}

\section{Hypothesis 1: Students do not have problems in their English language learning.}

Data were collected from the students to find out their language problems and the descriptive analysis clearly indicated the grammatical knowledge of the students and their weakest area in grammar and vocabulary.

Table 1. Problems of the high school students in English Language learning

\begin{tabular}{lll}
\hline S.No & Components of English & Percentage (\%) \\
\hline Grammar & \\
\hline 1 & 'Be' verbs & 72.19 \\
\hline 2 & Tense & 53.52 \\
\hline 3 & Article & 34.08 \\
\hline 4 & Sentence Pattern & 53.57 \\
\hline 5 & Direct and Indirect Speech & 11.06 \\
\hline 6 & Active and Passive Voice & 45.16 \\
\hline Vocabulary & \\
\hline 7 & Synonyms and Antonyms & 23.15 \\
\hline 8 & Prefix and Suffix & 50.60 \\
\hline 9 & Singular and Plural & 36.43 \\
\hline Overall percentage of grammar and Vocabulary & 42.19 \\
\hline
\end{tabular}




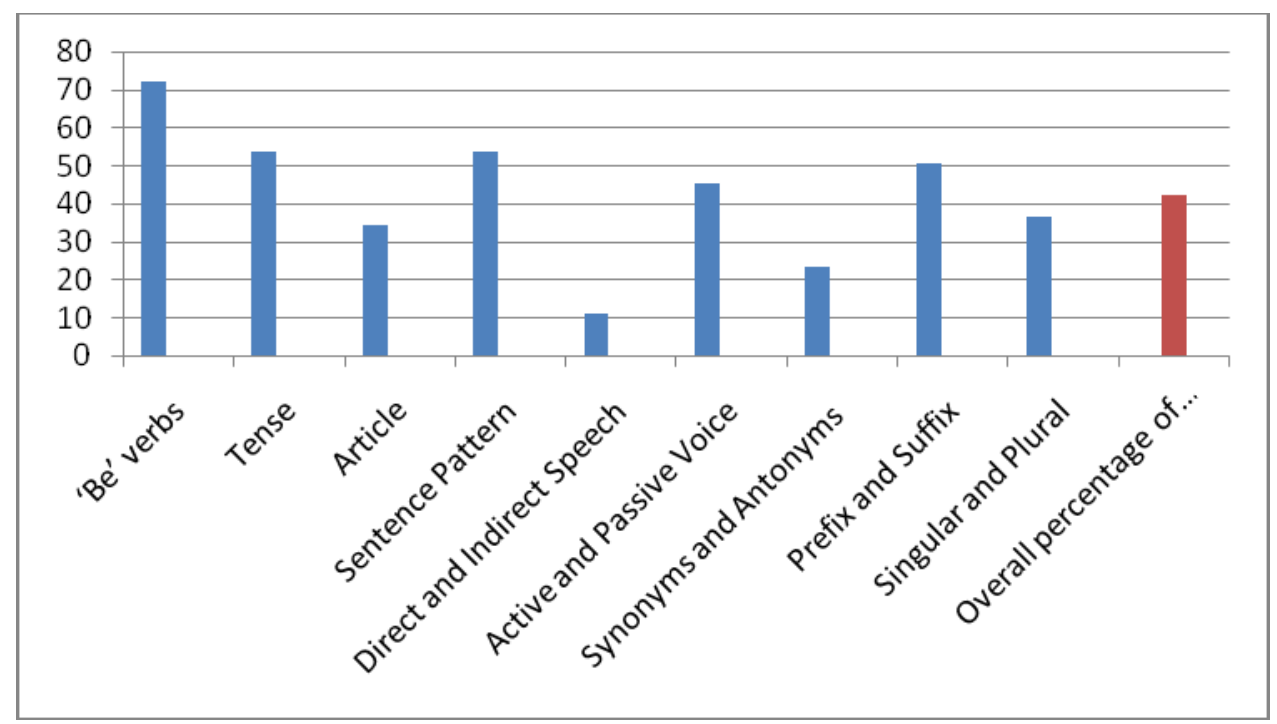

Figure 2. Problems of the high school students in English language learning

From the above data it is clear from the 'Overall percentage of grammar and Vocabulary' 42.19 that students have problems in their language learning. So, the hypothesis is not accepted. This finding is in line with the view of Sujata and Tiwale (2013) who stated that English is learnt with poor standards at schools. Students are poor in the grammar of Direct and Indirect Speech (11.06 \%). They are at average level in Tense (53.52\%), Sentence Pattern (53.54\%), Prefix and Suffix (50.60\%). It is obvious that students are at below average level in Article (34.8\%), Singular and Plural (36.43\%) and Synonyms and Antonyms (23.15\%). But students are better is be form verbs which is very basic in English. Hence it was found that students have problems in their English language. Bhoi (2013) pointed out the reasons for poor performance of the students. Students did not care to develop listening, speaking, reading and writing. The major challenges for students poor performance are that students from rural and underdeveloped areas, tribal background, economically backward society and uneducated families. Sikand (2012) clearly pointed out that frequent absent of Teachers and students, overcrowded classes, no proper attention to the students, no magazine provision to the students, and no English environment neither at schools not at home are the major causes for their poor performance. Bhaskar David (2013) was of the opinion that in rural schools students are not trained properly to speak, read and write in English at schools. Low self-esteem and lack of motivation to the learners, insufficient resources at school, overcrowded classes, and insufficient attention to the learners are the major contributors for their language inefficiency.

\section{Hypothesis 2: Technology Enabled Psycho-NLP strategy is effective.}

To analyse the hypothesis, differential analysis was done to distinguish the difference in their Spoken English with the scores in pre test and post test. The below table illustrates the difference in their spoken English.

Table 2. Spoken English difference before and after the experimentation

\begin{tabular}{|c|c|c|c|c|c|c|c|c|}
\hline \multirow{2}{*}{$\begin{array}{l}\text { Experimental } \\
\text { Group }\end{array}$} & \multirow[t]{2}{*}{$\mathbf{N}$} & \multirow[t]{2}{*}{ Mean } & \multirow[t]{2}{*}{ SD } & \multicolumn{3}{|c|}{ Percentiles } & \multirow[t]{2}{*}{$\mathbf{Z}$} & \multirow[t]{2}{*}{$\mathbf{P}$} \\
\hline & & & & $25^{\text {th }}$ & $\begin{array}{l}\mathbf{5 0}^{\text {th }} \\
\text { (Median) }\end{array}$ & $75^{\text {th }}$ & & \\
\hline Pre-test & 24 & 47.38 & 15.542 & 37.75 & 48.50 & 54.75 & -3.887 & 0.000 \\
\hline Post-test & 24 & 72.29 & 23.198 & 45.50 & 80.50 & 93.75 & & \\
\hline
\end{tabular}

*significant at 0.01 level 


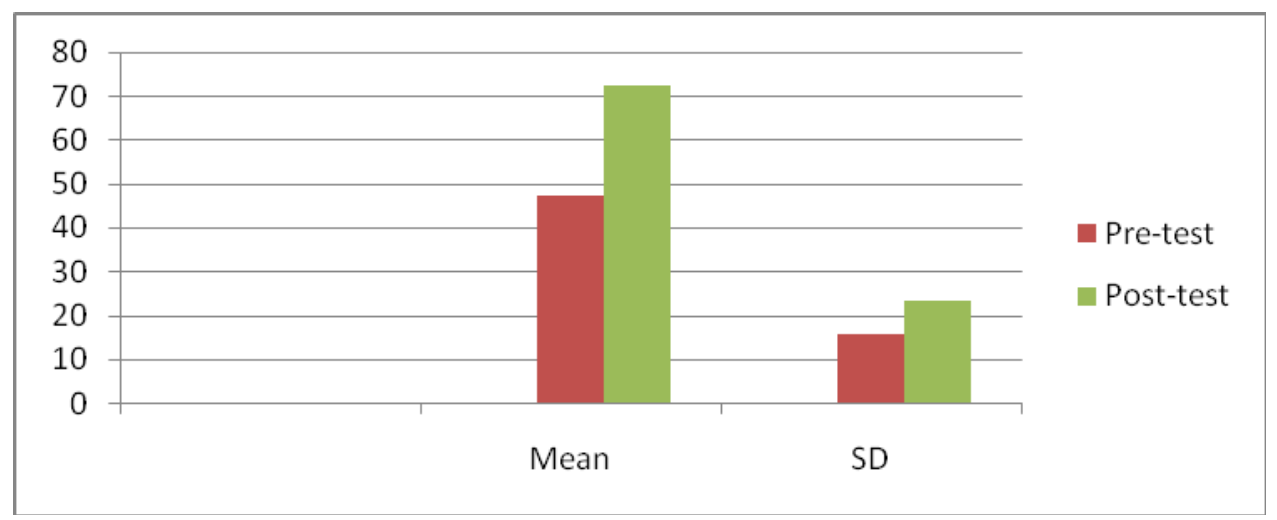

Figure 3. Spoken English difference before and after the experimentation

The $p$ value 0.000 with $Z=-3.887$ derived from wilcoxen signed rank test clearly explains that significant difference exists among students before the treatment and after the treatment with regard to Spoken English. Mean value (72.29) after the treatment is higher than that of the before treatment. This clearly showed that Spoken English after the treatment was much improved. This finding is supported by the finding of previous study conducted by Mally and Dilts (1990) who developed a spelling strategy for children based on NLP. Results of their study indicated that the experimental group students had significant improvements in spelling from the pre test to post test compared to the control group students Cited by Kudliskis (2009). So, the hypothesis is accepted. It is clear that Technology enabled Psycho-NLP strategy was found effective for improving spoken English of Std. IX students.

Table 3. Table showing positive and negative ranking of the students in spoken English

\begin{tabular}{ccccc}
\hline Groups & Ranks & N & Mean Rank & Sum of Ranks \\
\hline \multirow{2}{*}{$\begin{array}{c}\text { Experimental } \\
\text { Group }\end{array}$} & Negative Ranks & $2^{\mathbf{a}}$ & 7 & 14.00 \\
\cline { 2 - 5 } & Positive Ranks & $22^{\mathbf{b}}$ & 13 & 286.00 \\
\hline Post test - Pre test & Ties & $0^{\mathbf{c}}$ & & \\
\cline { 2 - 5 } & Total & 24 & & \\
\cline { 2 - 5 } & & &
\end{tabular}
a. $\quad$ Post test $<$ Pre test
b. $\quad$ Post test $>$ Pre test
c. $\quad$ Post test $=$ Pre test

Further analysis indicated that 22 students had got higher score in Spoken English and only 2 students had got less score in Spoken English. From the tie score $0^{c}$ it was found that all the students were found to have difference in their improvements. Spoken English of the students had been improved. Thus Technology Enabled Psycho-NLP strategy was found to be effective.

\section{Major Findings of the Study}

1. Technology enabled Psycho-NLP strategy was found effective for improving spoken English of Std. IX students.

2. Students have problems in their English language.

\section{Recommendations for Policy Making}

Research especially any educational research is expected to contribute for policy making based on the findings of the research. The present study had contributed for policy making in order to improve the spoken English of the students.

1. An orientation programme on 'Technology enabled Psycho-NLP' has to be given to the teachers to imbibe this model in their teaching. 
2. Training programmes on NLP is being conducted around the world today. Teachers could be motivated to participate in the training programmes to equip themselves in NLP.

3. Since this model is interrelated with technology, teachers have to be trained to use technology.

4. NLP could be integrated as a unit in psychology in Teacher Education Curriculum so that student teachers may be trained in their teacher education programme itself.

5. NLP may be included as one of the curriculum transactional strategies of English language teachers at school level.

\section{Conclusion}

Singh (2010) viewed that Today's challenges in ELT are such as mixed ability of high cost books and learning materials, exam oriented teaching, lack of students (teachers), lack of motivation, administrative problems, lack of media usage, journals, books, balance between mother tongue and English. Cathy (2012) quoted the following views of different authors. Teacher beliefs play an important role in instructional decision-making and teaching practices (Johnson, 1994; Shavelson \& Stern, 1981; Tillema, 2000; Wong, 2010). Teacher perceptions in regard to form-focused instruction have a great impact on whether they will incorporate grammar teaching in their classrooms (Fox, 1993; McCargar, 1993; Musumeci, 1997; Schulz, 1996). Several studies had been conducted to investigate teacher beliefs regarding grammar instruction (Edilian, 2009; Farrell, 1999; Farell \& Lim, 2005; Golombek, 1998; Ng \& Farrell, 2003; Richards, Gallo, \& Renandya, 2001; Wang, 2009; Yim, 1993). Farrell and Lim (2005) examined two English teachers' beliefs of grammar teaching in an elementary school in Singapore. The teachers believe that grammar instruction and providing grammar exercises for students are necessary. In addition, Wang (2009) reported in a study that the teachers agreed that grammar drills are important in language teaching and learning. Nevertheless, they also believed that students needed communicative activities to enhance their speaking ability. Similarly, Richards, Gallo, and Renandya (2001) reported that the teachers believe that explicit grammar instruction is essential in L2 learning, although they claimed that they adopted CLT in their teaching (Cathy, 2012). To conclude it is essential to mind from this study that Grammar and vocabulary plays a vital role for learning English. The result of present experiment strongly recommends that Technology enabled Psycho-NLP has contributed to the extent for improving the Spoken English of rural students.

\section{References}

American Psychological Association. (1972). Ethical standards of psychologists. Washington, DC: American Psychological Association.

Beckett, M. (2006). Project Based Second and Foreign Language Education. Information Age Publishing Inc..

Betagai Gangadhar. (2013). Impact of English Language Teaching on the communication skills of rural students, International Journal on English Language and Literature, 1.

Cathy Chin Yin Wing. (2012). The Role of Grammar in Communicative Language Teaching: An Exploration of Second Language Teachers' Perceptions and Classroom Practices. Electronic Journal of Foreign Language Teaching, 9(1). Retrieved from http://e-flt.nus.edu.sg/

Collingwood Chris. (2016). NLP, Psychology, Psychologist. Retrieved April 9, 2016, from www.inspirative.com.au/nlp-psychology/

David, Bhaskar T. (2013). The importance of speaking English to Rural students. ELT Weekly. Retrieved from http://eltweekly.com/2013/05/the-importance-of-speaking-english-to-rural-students-by-t-bhaskar-david/\#sth ash.68tgCorC.72ij8q8s.dpbs

Good Therapy Organisation. (2016). Retrieved April 9, 2016, from www.goodtherapy.org/learn-about-theraphy/types/neuro-linguistic-programming

Hauchar Nadine, (2016). Progressive education plus training and wellness centre, North America. Retrieved April 9, 2016, from www.progressiveplus.com/personal-development/neuro-linguistic-psychology-nlp

Karunaratne, M. (2010). Neuro-linguistic programming and application in treatment of phobias. Complementary Therapies in Clinical Practice, 16(4), 203-207. http://dx.doi.org/10.1016/j.ctcp.2010.02.003

Kudliskis Voldis, \& Burden Robert. (2009). Applying 'what works' in psychology to enhancing examination success in schools: The potential contribution of NLP. Thinking Skills and Creativity, 4, 170-177. http://dx.doi.org/10.1016/j.tsc.2009.09.002

Leask, M. (Ed.) (2001). Issues in teaching using ICT. London: Routledge Falmer. 
Milroad, R. (2004). The role of NLP in teachers' classroom discourse, ELT Journal, 58(1), 28-37.

Mohanty, (2012). English Language learning must go in hand with multilingualism, Importance English, e-paper. Retrieved from www.thehindu.com/opinion/op-ed/english-language-learning-must-go-hand-in-hard-with-multilinguia/atricl e3992238ece

Pegrum, M. (2009). From blogs to bombs: The future of digital technologies in education. Crawley, WA:

Pishghadam Reza, Shayesteh Shaghayegh, \& Shapoori Mitra. (2011, July). Validation of an NLP Scale and its Relationship with Teacher Success in High Schools. Journal of Language Teaching and Research, 2(4), 909-917. Academy Publisher Manufactured in Finland. http://dx.doi.org/10.4304/jltr.2.4.909-917

Ranjan Chitta Bhoi. (2013). Learning English language in India: Challenges and Opportunities. Languages in India, 13(8).

Saman, T. (2006). Effective ways of teaching and learning English through NLP Techniques, Department of English Language Teaching, Institute of Educational Sciences, Gazi University, Ankara.

Sikand Yoginder. (2012). India: Crisis in Rural Education. Retrieved from http://www.countercurrents.org/sikand211012.htm

Singh. (2010). English Language Teaching: A reflection on Challenges ahead, special lecture at National seminar on English Teaching at Sindri college, Sindri.

Sreenivasulu Reddy. (2012). Teaching/Learning English as a Second Language in India. Language in India, 12. Retrieved from www.languageinindia.com

Tosey Paul, \& Mathison Jane. (2010). Neuro Linguistic Programming as an innovation in education and teaching. Innovation in Education and Teaching International, 47(3), 317-326. http://dx.doi.org/10.1080/14703297.2010.498183

Trucano, M. (2012). Information and communication technologies. In Petrinos, HA (Ed.), Strengthening Education Quality in East Asia: System Assessment and Benchmarking for Education Results. SABER/UNESCO/The World Bank UWA Publishing. Retrieved from http://doc.iiep.unesco.org/cgi-bin/wwwi32.exe/\%5Bin=epidoc1.in\%5D/?t2000=031000/(100)

Zorica Antic. (2006). Neuro Linguistic Programming - The Link between Medicine (Neurology) and Language Teaching. Medicine and Biology, 13(2), 123-126.

\section{Copyrights}

Copyright for this article is retained by the author(s), with first publication rights granted to the journal.

This is an open-access article distributed under the terms and conditions of the Creative Commons Attribution license (http://creativecommons.org/licenses/by/4.0/). 